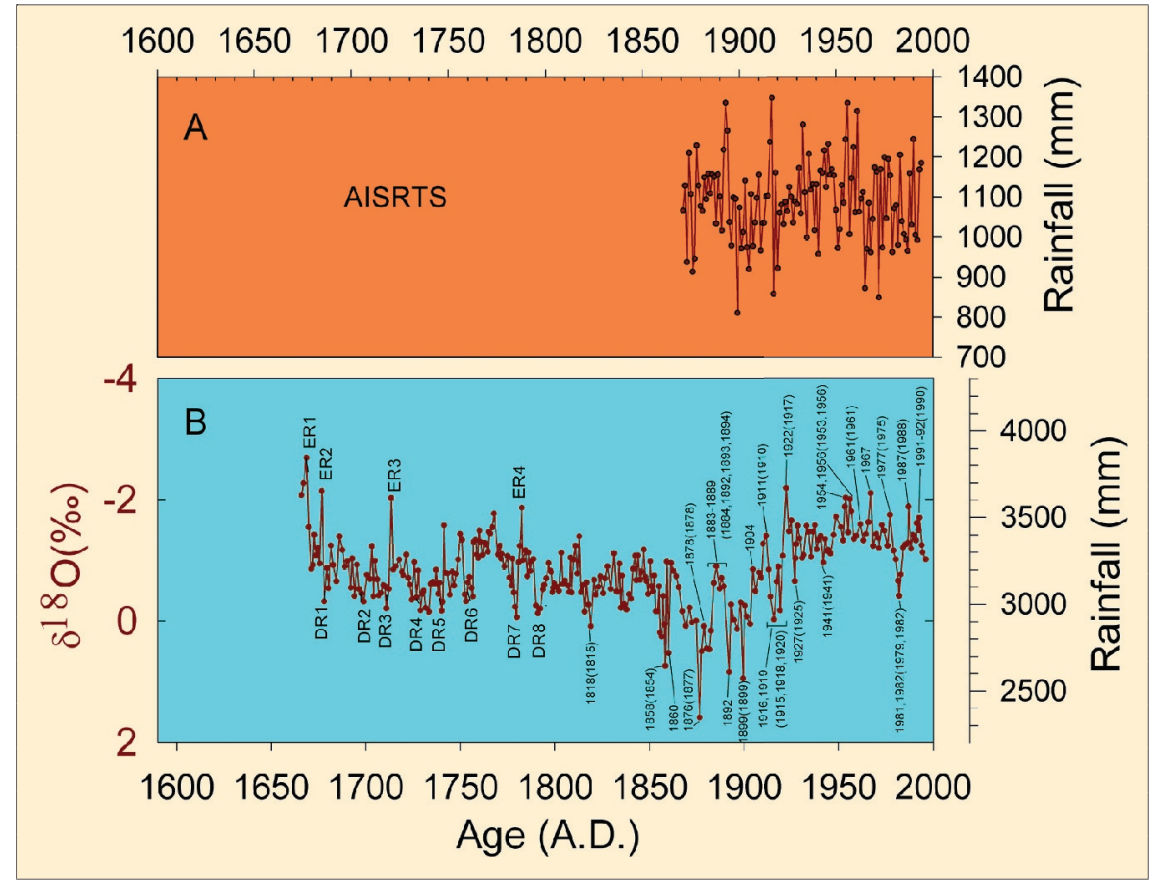

Fig.2: (a) The all India summer rainfall time series (AISRTS) for the period 1871-1994 based on data from 306 stations. (b) $\delta^{18} \mathrm{O}$ versus age obtained from lamination counting. The annual nature of the laminations is supported by the presence of bomb ${ }^{14} \mathrm{C}$ at the tip and agreement between the base ${ }^{14} \mathrm{C}$ age $(210 \pm 100 \mathrm{Yr} \mathrm{BP})$ and the total number of laminations (331). Scale for the rainfall reconstruction is shown on the right. Depleted and enriched $\delta^{18} \mathrm{O}$ signals coincide with excess and deficient rainfall years observed in the AISRTS. The year of their occurrence in the stalagmite is shown by the numbers outside brackets, in the AISRTS by numbers inside brackets. Numbers ER-1 to 4 and DR-1 to 8 are excess and deficient rain years observed before the period covered by instrumental data.

fall years ( 40\%) observed in AISRTS are registered in the stalagmite, while most of the excess rainfall years ( $86 \%)$ are recorded. A possible reason could be the proximity of the cave site to the coast, which would ensure that there were frequent rains due to orographic uplifting of clouds. Hence, a deficiency of rain may not have been experienced at the cave site despite a deficiency
Rainfall Before Instrumental Record (before AD 1813)

Low rainfall events DR7 and DR8 may coincide with the devastating droughts recorded during 1777 and 1796. Other events such as DR1 to DR6 should indicate extremely dry years. Growth in the stalagmite most probably took place when rainfall was high (near ER-1; 1666). A peculiar feature of the rainfall reconstruction is that none of the deficient rainfall conditions observed before 1800 are comparable in magnitude to the deficient years that occurred around 1900. However, the average rainfall before $\sim 1930$ did remain lower than that during 1930 1996. In the reconstruction, all the deficient years (except 1892) and all the excess years (except 1967 and 1905) correlate with similar events in AISRTS. This suggests that there is a high possibility that the extreme events shown by ER1 to ER4 and DR1 to DR8 occurred countrywide.

\section{REFERENCES}

Dansgaard, W., 1964: Stable isotopes in precipitation. Tellus, 16, 436-468.

Yadava, M.G., Ramesh, R. and Pant, G.B.: Past monsoon rainfall variations in peninsular India recorded in a 331 year old speleothem. (Submitted to The Holocenel.

Yurtsever, Y. and Gat, J.R., 1981: Atmospheric waters In Stable Isotope Hydrology: Deuterium and Oxygen-18 in the Water Cycle. Technical Report Series No. 210. (Gat, J.R. and Gonfiantini, Eds.), 103-142, IAEA, Vienna.

\title{
The Potential of Oxygen Isotopes in Diatoms as a Paleoclimate Indicator in Lake Sediments
}

\author{
Angela L. Lamb ${ }^{1}$, Melanie J. Leng ${ }^{2}$, Philip A. Barker ${ }^{3}$ and David W. Morley ${ }^{4}$ \\ ${ }^{1}$ School of Biological \& Earth Sciences, Liverpool John Moores University, UK; a.lamb@livjm.ac.uk \\ ${ }^{2}$ NERC Isotope Geosciences Laboratory, British Geological Survey, UK; mjl@nigl.nerc.ac.uk \\ 3Department of Geography, Lancaster Environment Centre, Lancaster University, UK; p.barker@lancaster.ac.uk \\ 4Environmental Change Research Centre, Department of Geography, University College London, UK; d.morley@ucl.ac.uk
}

Oxygen isotope ratios $\left(\delta^{18} \mathrm{O}\right)$ measured in authigenic minerals are a valuable means of assessing paleoclimate, recording the ambient water temperature and $\delta^{18} \mathrm{O}$ composition of the lake water at the time of formation (see Leng and Marshall, 2004). $\delta^{18} \mathrm{O}$ measured from lake carbonates (authigenic carbonate, ostracods, etc.) has become a well-established paleoclimate technique, but in di- lute and non-alkaline lakes where carbonates are rare, there are only a few suitable alternatives. The measurement of $\delta^{18} \mathrm{O}$ in biogenic silica (mainly diatoms) is being increasingly utilised in low carbonate lakes (e.g. Barker et al., 2001; Shemesh et al., 2001). Diatoms are photosynthetic algae that secrete an internal shell composed of opaline silica $\left(\mathrm{SiO}_{2}-\mathrm{H}_{2} \mathrm{O}\right)$ and are present in most lake sediments apart from some very alkaline lakes (typically $\mathrm{pH}>9$ ), or lakes where silica is limited (Barker et al., 1994). Here we discuss the types of lakes that are most suitable for this technique, the information that can be generated, and the potential problems.

\section{The Effect of Lake Location on $\delta^{18} 0_{\text {diatom }}$ Interpretation}

The majority of lakes, for which oxygen isotope ratios from diatom silica 


\section{Science Highlights}

have been successfully employed are in high latitude or altitude locations. The reasons for this lie in the nature of these lakes; diatoms are generally found in relatively high concentrations in low residence, well mixed, open lakes where diatom productivity is higher than other organisms. The water in these lakes reflects changes in the hydrological conditions of the lake basins (e.g. Leng et al., 2001, Barker et al., 2001) or the isotopic composition of precipitation (e.g. Shemesh et al., 2001; Jones et al., 2004, Rosqvist et al., 2004). Commonly, such lakes have low $\delta^{18} \mathrm{O}$ variability, reflecting changes in temperature or the source of precipitation, rather than evaporation, except perhaps in low latitude lakes. However, diatoms may only record conditions during a specific season, for example the vernal mixing period in temperate lakes, or in high altitude/latitude lakes, during the ice-free summer months when temperatures are highest, runoff is heaviest, and nutrients are washed in from the catchment (Jones et al., 2004). By contrast, in low-altitude,

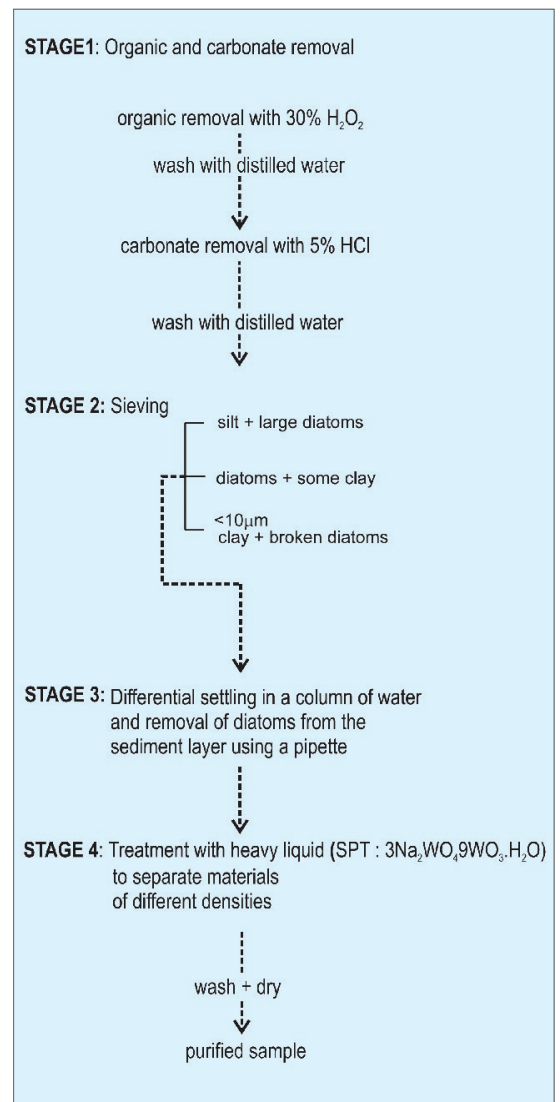

Fig. 1: Flow diagram showing the four-stage cleaning method for concentrating diatoms for $\delta^{18} \mathrm{O}_{\text {diatom }}$ analysis from lake sediments. Adapted from Morley et al. (2004).

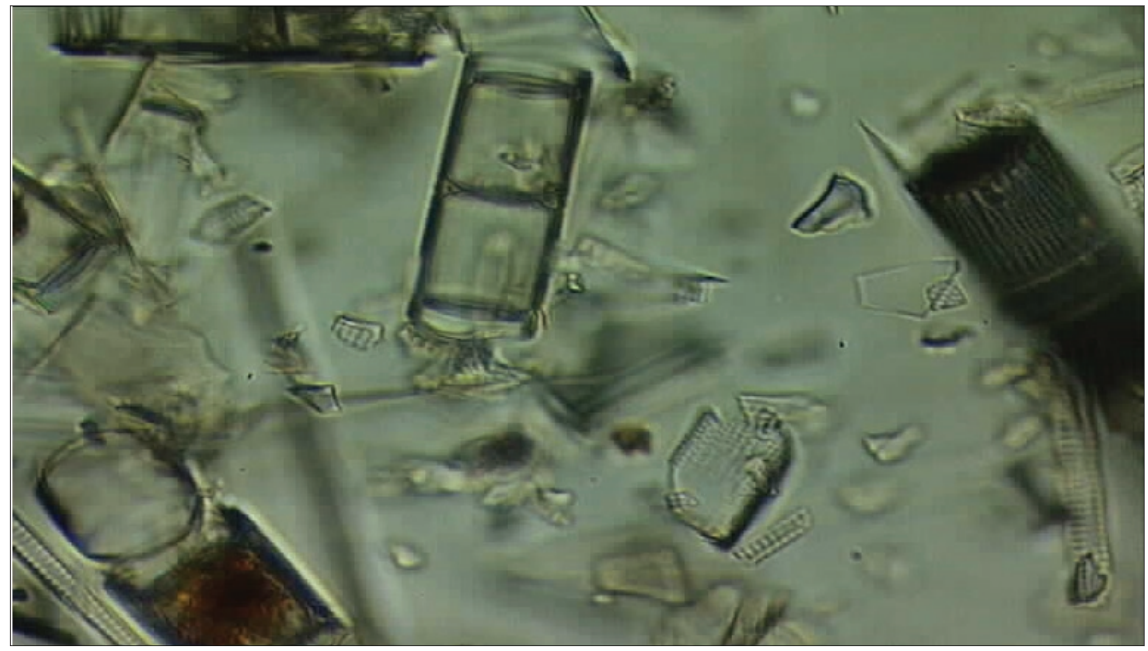

Fig. 2: Light microscope image of a sediment sample from Lake Tilo, Ethiopia. The sample is shown before sieving but after removal of carbonates and organics. Various diatom species are evident (predominantly Aulacoseira granulata), along with a significant volcanic glass shard component. Photo courtesy of Philip Barker.

mid-latitude and tropical lakes, higher temperatures may allow some diatom growth throughout the year, but this does depend on other mechanisms such as the seasonality of lake-water mixing and nutrient availability. Theoretically, diatom oxygen isotopes should record a seasonally averaged evaporation to precipitation balance of such lakes (e.g. Lamb et al., 2003), but few studies have been undertaken, in part because of the difficulty of separating the diatoms from the rest of the sediment.

\section{Sample Cleaning}

Analysis of the oxygen isotope composition of diatom silica requires samples that are almost pure diatomite, since the method most widely used (fluorination techniques) will also liberate oxygen from other components in the sediment, for example, silt, clay, volcanic glass (tephra), carbonates and organic matter. This is in contrast to the analysis of oxygen isotope ratios in carbonates, which only requires the removal of organic material and verification that the carbonate is authigenic. The precision of the $\delta^{18} \mathrm{O}_{\text {diatom }}$ technique is several times lower ( 0.2-0.5\% as opposed to $<0.1 \%$ o) than for $\delta^{18} \mathrm{O}$ in authigenic carbonate, mainly due to the relative difficulty in breaking the Si-O bond, but also because of the higher risk of contamination in the diatom samples. Clay, silt and tephra can be difficult to remove from sedi- ments and can have a large influence on $\delta^{18} \mathrm{O}_{\text {diatom }}$ values. However, removal of these contaminants can be achieved via a series of cleaning stages, including organic and carbonate material removal, sieving, differential settling and heavy liquid separation (Morley et al., 2004; Fig. 1). In particular, sieving at various sizes is an important step in removing clay and silt; however, silt and tephra are often within the size range of the diatom frustules and thus cannot be easily removed (Fig. 2). Even small amounts of silt and tephra can have a significant effect on $\delta^{18} \mathrm{O}_{\text {diatom }}$ because these materials often have $\delta^{18} \mathrm{O}$ values that are significantly lower than the $\delta^{18} \mathrm{O}_{\text {diatom }}$ values (Lamb et al., 2003, Morley et al., 2004).This emphasizes the need for microscopic examination of every sample and a cleaning method that is individually tailored to the core being analysed. An alternative approach to heavy liquid separation, currently being used at Lancaster University, is gravitational split-flow thin fractionation (SPLITT) developed by J.C. Giddings at the University of Utah and first applied to the separation of diatoms at the University of Jülich (Schleser et al., 2001). The advantages of SPLITT fractionation are high throughput by continuous flow, small losses, and sometimes the ability to isolate specific taxa (where they have different size, density and/or shape). It also avoids the need to introduce other products to the sample. Some 
SPLITT separation of diatoms from Lake Rutundu, Mt Kenya

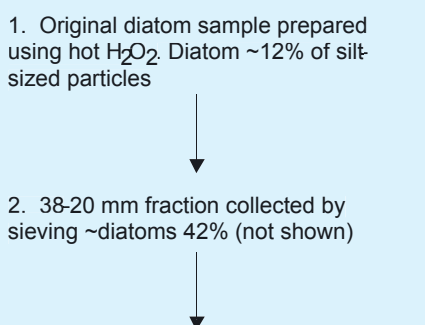

3. Sieved fraction processed with SPLITT

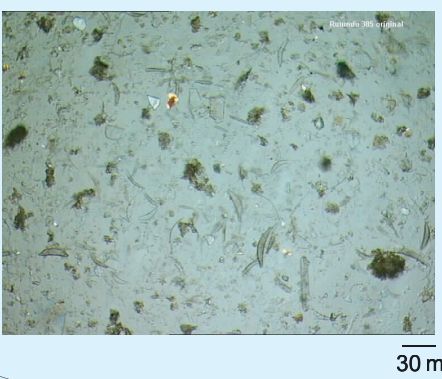

$\triangle$

SPLITT fraction A diatoms $95 \%$

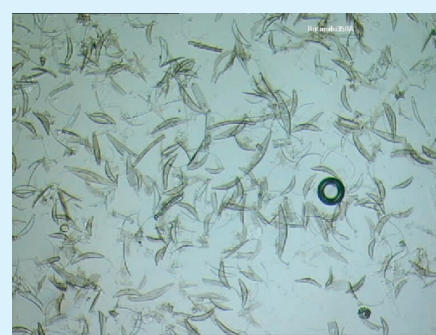

SPLITT fraction B diatoms $17 \%$

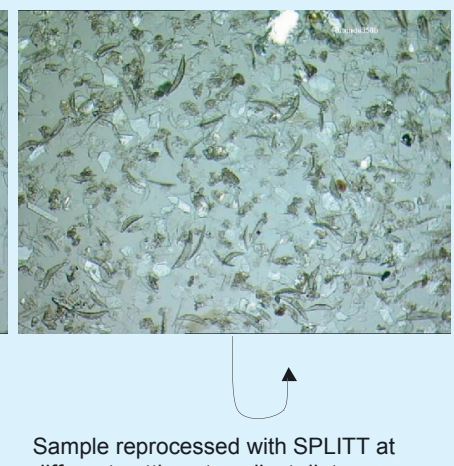

different settings to collect diatoms

4. Samples checked for purity and dried for isotope analysis

Fig. 3: Procedure used in the extraction of diatoms from Lake Rutundu, Mt Kenya. Diatom concentration is estimated optically and expressed per number of silt-sized particles. In this case, sieving of the chemically cleaned material was not sufficient to obtain pure samples. SPLITT separation produced one fraction with about 95\% diatoms and another with a mixture of diatoms and silt. Fraction (B) could be recycled under different experimental conditions to try and extract the remaining diatoms. Additional processing of sample A could improve the concentration of diatoms further.

results of SPLITT separation are shown in Figure 3.

\section{Comparing $\delta^{18} 0_{\text {carbonate }}$ and $\delta^{18} 0_{\text {diatom }}$}

It is rare that both carbonate and diatom silica exist simultaneously in lakes in significant concentrations, due to the influence of $\mathrm{pH}$. Lake $\mathrm{pH}$ is a central controlling factor in diatom dissolution rates as it controls the dissociation of silicic acid (e.g. Barker et al., 1994). Lakes in carbonate catchments, where silica is not limited and that have a $\mathrm{pH}$ of 7 or 8 , can sometimes support both carbonates and diatoms in high concentrations, but this is quite unusual. As a result, only two recent studies have measured $\delta^{18} \mathrm{O}$ in both diatom silica and authigenic carbonate (Leng et al., 2001; Lamb et al., 2003). A small Ethiopian Rift Valley lake core record shows similar $\delta^{18} \mathrm{O}_{\text {diatom }}$ and $\delta^{18} \mathrm{O}_{\text {calcite }}$ values through the early Holocene, suggesting that both diatom silica and calcite precipitated from the lake water at the same time during the year and were subject to the same climate controls (Lamb et al., 2003). In contrast, $\delta^{18} \mathrm{O}_{\text {diatom }}$ and $\delta^{18} \mathrm{O}_{\text {calcite }}$ values from a temperate setting in southern Turkey show entirely different curves and therefore suggest that diatom silica is not always a direct substitute for carbonate-based isotope analysis. The reasoning for this is thought to be that the diatoms grow predominantly in spring on the Anatolian plateau, thus reflecting the spring thaw lake-water composition, while the calcite precipitates during the summer months (Leng et al., tings, and thus seasonal differences in diatom production, will lead to different aspects of climate being recorded by $\delta^{18} \mathrm{O}_{\text {diatom, }}$, but equally, carbonate-based records may be only indicative of conditions during a short summer season.

\section{Future Potential}

Many $\delta^{18} \mathrm{O}_{\text {diatom }}$ studies where contamination problems have been overcome are successfully produc2001). Clearly different climatic set- ing sensitive paleoclimate records, mostly reflecting changes in the source, temperature and amount of past precipitation, and local lake hydrology. Diatomaceous sediments from important lakes such as Baikal and Malawi are now being studied to produce multi-millennial isotope records. The current push to improve cleaning methods (Barker et al., 2003; Lamb et al., 2003, Morley et al., 2004) should soon start yielding significant improvements in accuracy, and open up the methodology to a broader range of lakes.

\section{ACKNOWLedgements}

Many people have helped in the production of this article and in the technical aspects of analysis. Peter Greenwood and Hilary Sloane are thanked for their contribution to the setting up of the technique at the NERC Isotope Geosciences Laboratory. Sophie Theophile and Patrick Rioual did some of the early cleaning experiments at University College London. Diatom separation using SPLITT is funded by NERC grant NER/B/S/2002/00512 to Philip Barker and Melanie Leng. Sarah Watkins, the technician on the project, produced the diatom separations and the images in Figure 3. Alayne Street-Perrott made material from Lake Rutundu available. The samples cleaned with SPLITT are to be analyzed at NIGL under the NERC award IP/800/1103.

\section{REFERENCES}

Barker P.A., Street-Perrott F.A., Leng M.J., Greenwood P.B., Swain D.L., Perrott R.A., Telford R.J., and Ficken K.J., 2001: A 14,000-year oxygen isotope record from diatom silica in two alpine lakes on Mt. Kenya. Science, 292, 2307-2310.

Jones, V.J., Leng, M.J., Solovieva, N., Sloane, H.J. and Tarasov, P., 2004: Holocene climate on the Kola Peninsula; evidence from the oxygen isotope record of diatom silica. Quaternary Science Reviews, 23, 833-839.

Leng M.J., Barker P., Greenwood P., Roberts N., Reed J., 2001: Oxygen isotope analysis of diatom silica and authigenic calcite from Lake Pinarbasi, Turkey. Journal of Paleolimnology, 25, 343-349.

Leng, M.J. and Marshall, J.D. 2004: Palaeoclimate interpretation of stable isotope data from lake sediments. Quaternary Science Reviews, 23 811-831.

Shemesh, A., Rosqvist, G., Rietti-Shati, M., Rubensdotter, L., Bigler, C., Yam, R. and Karlen, W. 2001 Holocene climatic change in Swedish Lapland inferred from an oxygen-isotope record of lacustrine biogenic silica. The Holocene, 11, 447-454.

For full references please see: www.pages-igbp.org/products/newsletters/ref2004_1.html 